\title{
Self-efficacy and Its Relation to ESL Writing Proficiency and Academic Disciplines
}

\author{
Saeid Raoofi (Corresponding author) \\ Department of English Language Education, Farhangian University, Sanandaj, Iran \\ E-mail: raoofisaeed2020@yahoo.com \\ Jalal Gharibi \\ Department of Educational Science, Farhangian University, Sanandaj, Iran \\ E-mail: jgharibi@yahoo.com \\ Hassan Gharibi \\ Department of Pschology, Payame Noor University, Tehran, Iran \\ E-mail: hgharibi33@gmail.com
}

Received: 18-02-2017

Accepted: 13-04-2017

Advance Access Published: July 2017

Published: 01-09-2017

doi:10.7575/aiac.ijalel.v.6n.5p.127

URL: http://dx.doi.org/10.7575/aiac.ijalel.v.6n.5p.127

\begin{abstract}
Writing is an essential skill for academic development within any disciplinary area. Despite the rapidly growing body of research on the various aspects of second language writing, research on writing self-efficacy remains scarce. This study investigated the relationship the between writing self-efficacy and writing proficiency in English as a second language. In this cross-sectional study, 304 Malaysian undergraduate students completed a writing self-efficacy questionnaire. The participants' writing proficiency was assessed using two different writing tasks. The results showed that there was a significant difference in writing self-efficacy among the three writing proficiency groups. It was also found that science students had significantly higher writing self-efficacy than those in social sciences. Limitations of the study and Implications for second language writing instruction are also discussed.
\end{abstract}

Keywords: second language writing, self-efficacy, writing proficiency, English as a Second Language (ESL), undergraduate students

\section{Introduction}

One of the most important factors affecting students' learning and motivation is self-efficacy ((Pajares, 1996, 2006; Schunk, 2003). Self-efficacy is an essential component of the social-cognitive theory. Self-efficacy is defined as "beliefs in one's capabilities to organize and execute the courses of action required to produce given attainments" (Bandura 1997, p. 3). Self-efficacy is affected by four ways known as sources of self-efficacy: mastery experiences, social persuasion, vicarious experiences and physiological states (Bandura, 1997). Among these sources, mastery experience is considered to be the most influential or the strongest factor affecting self-efficacy. Experiences of success and previous achievements are very instrumental in shaping self-efficacy beliefs. Indeed, previous success enhances the level of self-efficacy while past failures decrease it.

Numerous empirical studies have shown that self-efficacy has a significant relationship with language performance (Dwyer \& Fus, 2002; Hsieh, 2008; Mills, Pajares, \& Herron, 2006, 2007; Woodrow, 2011; Wu, Lowyck, Sercu, \& Elen, 2013). Results of these studies support the research findings in other areas such as math and L1 writing (Pajares, 1996, 2003; Pajares \& Johnson, 1996; Pajares \& Miller, 1994)) which revealed that self-efficacy is closely related to performance. Hsieh and Schallert (2008) conducted a study on 500 university students who were learning one of the three languages (Spanish, German and French) as a foreign language in the US. The study reported that self-efficacy appeared to be the most powerful predictor of language performance compared with the other predictor variables used in the study. Similarly, in a large scale study, Woodrow (2011) surveyed 738 EFL university students in China to examine the interplay between L2 performance and self-efficacy. The results of the study showed that perceived selfefficacy was significantly related to L2 writing performance.

Some researchers have attempted to investigate examined the association between language learning strategy use and self-efficacy beliefs (Magogwe \& Oliver, 2007; Tilfarlioğlu \& Cinkara, 2009; Wong, 2005) For example, Tilfarlioğlu and Cinkara (2009) examined the link between proficiency and self-efficacy among 175 EFL undergraduate students ranging in ages from 19 to 25 in Turkey. It was found that the higher level of perceived self-efficacy was significantly 
related to greater use of language learning strategies. Similarly, Wong's (2005) study of Malaysian ESL undergraduate students revealed that self-efficacy was positively related to strategy use.

Previous research also investigated the relationship between self-efficacy and affective factors such as attributions (reasons for success or failure in a given task or a particular skill) and anxiety (Cubukcu, 2008; Erkan \& Saban, 2011; Graham, 2006; Hsieh \& Kang, 2010; Hsieh \& Schallert, 2008; Woodrow, 2006, 2011). For example, in a study aimed at understanding how self-efficacy is related to attributions Hsieh and Kang (2010) found that Korean EFL students with low self-efficacy tended to ascribe language test results more strongly to uncontrollable and external factors such as luck, test difficulty and teacher than those with high self-efficacy. In contrast, students with high self-efficacy attributed language performance more strongly to controllable and internal factors such as effort than low self-efficacy students. The association between self-efficacy and attribution was also examined by Graham (2006). In a qualitative study of British students aged 16 to 18 , Graham (2006) found that students who had high self-efficacy attributed their lack of success in French language learning to controllable factors such as lack of effort or lack of appropriate strategies. On the other hand, those who had low self-efficacy attributed their failure in French to the uncontrollable factors such as lack of language learning ability

Erkan and Saban (2011) investigated the relationship between language anxiety and self-efficacy. They conducted a study on 188 Turkish university students to understand how writing self-efficacy, writing anxiety and writing performance are related one to another. The study found that L2 writing anxiety is negatively associated with both writing self-efficacy and performance. The relationship between writing self-efficacy and writing anxiety was also assessed by (Cheng, 2002). In a study focused on L2 writing anxiety among university students in Taiwan, Cheng (2002) discovered that, L2 writing self-efficacy emerged as the best predictor of L2 writing Anxiety. Mills et al. (2006) investigated the link between L2 self-efficacy and anxiety for university students who were learning French as foreign language in an American university. Mills et al. (2006) demonstrated that L2 reading and listening self-efficacy had a significantly negative link with reading and listening anxiety. Similarly, in a study of 275 ESL undergraduate and postgraduate students in Australia, Woodrow (2006) found that there were a significant negative relationship between ESL speaking anxiety and self-efficacy, and a significant positive relationship between ESL speaking anxiety and performance.

Although a substantial body of research has addressed self-efficacy in second/foreign language learning context, only a few studies have focused on documenting writing self-efficacy. Most of the studies to date have examined the association between self-efficacy and performance. Furthermore, some studies have investigated how self-efficacy interacts with general language proficiency, but there is a general lack of research in establishing the relationship between writing self-efficacy and writing proficiency. In particular, this study intends to address the following research questions:

(1) How is the ESL writing self-efficacy of Malaysian university students?

(2) Does writing proficiency affect writing self-efficacy?

(3) How do science students and social sciences students differ in their ESL writing self-efficacy?

\section{Methodology}

\subsection{Participants}

Three hundred and four Malaysian university students responded to a questionnaire and took a writing proficiency test, of whom twenty also participated in an interview. The participants were sampled out of approximately 1800 undergraduate students enrolled in a writing course at a Malaysian national university. Around $26 \%$ of these participants were males and $74 \%$ were female. All of the participants considered themselves as second language speakers of English. The dominant first languages were Malay, Chinese and Indian. Participants' ages ranged from 19 to 23 and they were all of Malaysian nationality.

The 304 participants were classified into three different levels of proficiency based on their scores in argumentative and descriptive writing tests. The student who got one standard deviation above mean (77.3) were placed in high level proficiency group while those students whose score was 1 standard deviation below the mean were assigned as low proficiency group. The intermediate group consisted of the students whose writing score was around the mean; that is, their scores were between 1 standard deviation below the mean or 1 standard deviation above the mean. As shown in Table 1, the participants were from different disciplines.. The number of respondents from sciences was higher than those from social sciences. 


\begin{tabular}{lll}
\hline \multicolumn{1}{c}{ Table 1. Respondents' Academic Major } & & \\
\hline English Language & 15 & Number of Respondents \\
Malay Language & 20 \\
Communication & 6 & \\
Arabic & 3 \\
Education & 27 \\
Economics & 18 \\
Landscape Architecture & 16 \\
Biotechnology & 24 \\
Doctor of Medicine & 25 \\
Occupational Health & 22 \\
Agriculture & 25 \\
Agribusiness & 17 \\
Animal Science & 12 \\
Chemistry & 12 \\
Food technology & 6 \\
Aerospace Engineering & 4 \\
Computer Engineering & 13 \\
Mechanical Engineering & 15 \\
Civil Engineering & 6 \\
Biomedical Science & 18 \\
\hline
\end{tabular}

\subsection{Instruments}

\subsubsection{Writing Self-efficacy Scale}

A writing self-efficacy questionnaire was created based on previous research. The items were adapted from a Writing Self-efficacy Questionnaire (Pajares, 2007; Pajares \& Valiante, 1999), and Motivated Strategies for Learning Questionnaire (MSLQ) (Pintrich, Smith, García, \& McKeachie, 1993). After the student interviews and expert review, the scale was also pilot-administered, and the pilot results revealed that the scale had a satisfactory reliability Cronbach's $\alpha=.85$. The final version of the modified questionnaire consisted of 12 items: 7 items from Pajares and Valiante's self-efficacy scale, 4 items from the MSLQ, and one item developed by the researcher.

\subsubsection{Interviews}

Semi-structured interviews were used to elicit in-depth information from ESL students about their writing experiences and writing self-efficacy beliefs. After collecting data through questionnaire and proficiency test, the interviews were conducted in the second phase of data collection. A sample of 20 participants was interviewed. The selection of participants for the interview was purposeful based on their agreement, their responses to the questionnaire and their performance on the writing tests. The interviews took between 15 to 20 minutes at different faculties of UPM depending on the availability and convenience of the interviewees. The questions of the interview were predetermined for all of the interviewees in the same order but there was some flexibility in following the conversation of the participants (Creswell, 2012) .The interviews provided the in-depth information about the degree of learners' self-confidence in writing that could not be obtained from the questionnaire. Interviews were used to elicit responses from the participants about the problems they face when writing in English and how do they approach the problems.

\subsubsection{Writing proficiency test}

This study employed descriptive and argumentative writing tasks to evaluate students' writing proficiency in English. The students were asked to write both an argumentative essay and a report using information provided in a table and a graph. The total score obtained on the two writing tasks represented students' English writing ability. Since the writing topics employed for this study were not previously given to the participants, the topic difference or topic familiarity was supposed to pose no great variation in the ESL writing score of the participants. It was essential to give participants novel topics because topic familiarity had been identified as an influential factor affecting writing performance (Stapleton, 2001).

The topics were general and hence they did not require any specific knowledge. The topics of writing task 1 and task 2 were respectively "Using the data provided, compare and analyze school enrolment in three countries in relation to income level" and "education is the most important factor on the development of a country". For the task one, participants were asked to spend 30 minutes on writing a report between 150 and 200 words while the second task 
required the participants to spend 45 minutes on writing an argumentative essay of at least 350 words. The first task made up $40 \%$ (40 marks) of the total writing score while the second one accounted for $60 \%$ (60 marks) of the whole score. Writing tests were conducted during regular time of their writing course class and they altogether took one hour and 15 minutes to complete them.

\subsection{Data analysis}

Statistical analyses were conducted using Statistical Package for Social Sciences ((SPSS) software, version 22. Descriptive statistics, independent samples t-test and one-way Analysis of Variance (ANOVA) were used for data analysis. For differences in self-efficacy between writing proficiency groups, One-way ANOVA with with Scheffe post hoc analysis was used. Differences in self-efficacy between science and social science students were examined using independent samples t-test. Qualitative data analysis was used to examine students' self-efficacy beliefs in L2 writing. The students' response to open-ended question were coded, and analysed to identify patterns and themes.

\section{Results}

\subsection{Quantitative results}

The participants were moderately confidant about their ability in the ESL writing, their self-efficacy indices about writing ranged from 30 to 99 . The overall mean score was 66 on a scale with a range from 0 to 100 . As expected, students indicated higher self-efficacy in certain aspects of writing; for example the mean score for students' confidence level in creating a one-page writing without having spelling mistakes was 72 , and it appeared to be higher in comparison with self-efficacy in writing a well-organized essay having a good introduction and body and conclusion. They also reported high self-efficacy in writing a letter in English about their likes and dislikes to a classmate $(\mathrm{M}=71)$, and, doing well in English writing assignments, $(\mathrm{M}=71)$. It was also found that the participants' writing self-efficacy in term of grammar was lower compared with the other writing self-efficacy aspects. Participant did not show high selfefficacy in being grammatically correct in their writing tasks. The item which assessed participants' self-efficacy beliefs in writing correct grammatical sentences had an overall mean of 62. This could be explained from the point that as individuals generally feel less confident when doing hard and challenging tasks compared with easy ones.

An analysis of the data revealed that only a small number of participants about (49 out of 304) reported to have either low or very low self-efficacy $(\mathrm{M}=$ below 50$)$, and 62 participants reported to have high or very high self-efficacy $(\mathrm{M}=$ above 75). However, the majority of the participants (193 out of 304) showed that they had writing self-efficacy at moderate to slightly high level, with their writing self-efficacy means ranging between 50 and 75 .

The ANOVA analysis revealed that there were significant differences in writing self-efficacy among three writing proficiency groups, $\mathrm{F}(2,301)=58.21, p=.00, \eta 2$ (eta-squared) $=.27$. The strength of relationship between writing proficiency and writing self-efficacy, defined by $\eta^{2}$ was strong as writing proficiency accounted for $27 \%$ of the variance of the writing self-efficacy. A brief description about classifying the ESL students into three writing proficiency groups is given here next. Post hoc analyses revealed that highly successful student writers had a significantly higher level of writing self-efficacy than moderately successful student writers who in turn showed significantly greater self-efficacy than less successful ones. Table 2 shows the ANOVA results.

Table 2. Differences in writing self-efficacy among three writing proficiency groups

\begin{tabular}{lcccccccc}
\hline Variable & \multicolumn{2}{c}{$\begin{array}{c}\text { Low } \\
(\mathrm{n}=49)\end{array}$} & \multicolumn{2}{c}{$\begin{array}{c}\text { Middle } \\
(\mathrm{n}=193)\end{array}$} & \multicolumn{2}{c}{$\begin{array}{c}\text { High } \\
(\mathrm{n}=62)\end{array}$} & & \multicolumn{1}{c}{$\boldsymbol{p}$ Value } \\
& Mean & SD & Mean & SD & Mean & SD & & \\
\hline Self-efficacy & 61.84 & 9.12 & 69.03 & 8.43 & 78.79 & 6.78 & 46.12 & .00 \\
\hline
\end{tabular}

Note. $P<0.05$

It was also found that participants in sciences $(M=7.12, \mathrm{SD}=.97)$, had a significantly higher level of writing selfefficacy than those majoring in social sciences $((\mathrm{M}=6.4, \mathrm{SD}=1.31), \mathrm{t}(302)=4.95, p=.00$. This suggests that the students in competitive fields of study such as medical science have higher sense of confidence about their ESL writing ability than those in social sciences such as education.

\subsection{Qualitative results}

Qualitative data seemed to corroborate and support the quantitative data. Most of the interviewed participants mentioned having medium level of writing self-efficacy. However, interviewees' responses vary in terms of the reasons they attributed to their level of confidence in writing. Some participants refer to the difficulty of writing task, inadequate grammatical knowledge, lack of practice, difficulty of writing a task in another language, while some others thought that lack of content was the main problem that they had when writing in English, they mentioned that they could not write well because they did not had good knowledge and information for their writing and this made writing difficult for them. Self-efficacy recorded in the interview data tended to support self-report data. Although, the two data types were very similar, they were not perfectly matched. For example, one of the respondents' mean score of writing self-efficacy reported to be 70 in the self-report data, while his assessment of his writing self-efficacy was 60 in the interview. 
From the interviewees' explanations about their own writing confidence, several factors emerged as important determinants in their self-efficacy evaluation. The factors included structural and grammatical knowledge of English language, mother tongue influence, writing practice, content knowledge for writing tasks, and task difficulty. Participants pointed to difficulty in finding suitable English words when writing in English. They found it difficult when translating their ideas and information into English. One of the participants said when she wrote in English she had difficulty in remembering the words that she needed and she tried to find some other words to use instead. These participants had their thoughts and ideas in their mother tongue and then put it in English and hence they faced many problems in finding equivalent words and structure between the two languages. Thus, naturally this would lead to ungrammatical sentences and word choice problems in their English writing.

Several participants mentioned writing was difficult for them because they believed that their grammar knowledge was not good and they needed to develop it. They said that grammar is a very important factor for getting a good grade in writing. One of the interviewees explained "I know the words and I have information for my writing, but it was very difficult to organize it, I am not confident about grammatical rules". Participants also pointed to practice and English writing experience as contributing to writing development. Some of them believed that they had not had enough practice and they had not enough ideas to put into their writing. They said they wrote in English on given tasks in school but it was not enough. When one of the interviewees was asked "how would you rate your writing ability?" she replied "I believe my writing is not good because still in think I need to write more and more."

The interviewees, who believed in their writing ability, said they frequently used English for their writings while those with low self-efficacy in ESL writing said they seldom wrote in English or only they wrote in English when they had to. The high self-efficacy interviewees also were more optimistic about enhancing their writing ability and showed more plans and strategies for developing their writing skill than those who felt less efficacious about their writing skill. They reported less or even had no specific plans to make their writing more developed and effective. In contrast high selfefficacy participants said that some techniques such as reading more, using writing models, seeking help from internet and increasing vocabulary helped them to write more properly. They also appeared to make more efforts and reported to try harder at enhancing their writing skill than low self-efficacy students.

Almost all of the students interviewed believed practice is a very important factor in developing writing skill, both high and low self-efficacy students believed that doing more writing exercises help them to make their writing more effective. However, those with high sense of writing efficacy were more specific about practice as they mentioned different types of practices such as writing essays, writing in blogs, writing diaries, writing letters, writing about interesting topics, and communicating in English, while the students with less writing efficacy were general about the practice effectiveness, they mentioned phases such as practicing more, writing more and doing more exercises.

The results also indicated that, the participants who believed in their witting ability make more controllable attributions - reasons for their success or failure in something over which they had control - for writing developments. For example one of the participants with high writing self-efficacy pointed to his strategies for his success and said "I ask my teacher and my friends, sometimes I practice more ... internet and I read more essays and articles". Students who had Low writing self-efficacy mentioned more uncontrollable attributions - reasons for their success or failure in something over which they had no control - such as lack of content for writing, and task difficulty. The qualitative results perfectly match with quantitative part in addressing the association between the writing proficiency and writing self-efficacy. The students who were highly proficient writers showed that they had higher level of writing self-efficacy than those who were less proficient writers.

\section{Discussion and Conclusion}

Results showed that the participants were moderately to highly confident about their ability in ESL writing. Within ESL context of Malaysia, the participants 'self-efficacy indices about writing ranged from 30 to 99 . The overall means score, was 69 on a scale with a range from 0 to 100. However, it should be noted that students showed lower levels of self-efficacy in writing grammatical sentences, and writing a well-organized essay compared to their self-efficacy in writing a one-page text without spelling errors or writing a letter to their friends. This is not surprising because students do not do essay writing as much as other types of writing such as text messaging or friendly letters in which grammatical errors go unnoticed. Another possible explanation may involve differences between academic writing and informal writing. Within L2 Learning contexts, L2 learners are more likely to be more familiar with L2 words, phrases and structure used in social communication rather than the language required for academic writing.

The students reported having relatively high writing self-efficacy. The reported high level of self-efficacy may have resulted from the effects of the writing course. Students in the writing course received explicit instruction concerning writing development and essay writing. Teachers and language mentors have a great role in shaping students selfefficacy beliefs. Instructors' behavior directly affects students' confidence in writing; as one of the important factors which affect the self-efficacy is modeling (Bandura 1997). Furthermore, it can be assumed that the course may have provided some opportunities for vicarious learning (Bandura 1977) as it involved some writing assignments. Bandura (1997) claimed that learners' self-efficacy in a particular task increases if they observe their friends or peers' successful task performance.

Results also revealed that highly students with high writing proficiency had a significantly higher level of writing selfefficacy than moderately proficient student writers who in turn showed significantly greater self-efficacy than students with low writing proficiency. The qualitative results perfectly match with quantitative part in addressing the association 
between the writing proficiency and writing self-efficacy This finding is consistent with a substantial body of previous research which indicates that language proficiency and language self-efficacy are closely related ((Magogwe \& Oliver, 2007; Mills et al., 2006; Rahimi \& Abedini, 2009; Tilfarlioğlu \& Cinkara, 2009; Wu et al., 2013). This result also confirms the argument that mastery experiences affect self-efficacy beliefs ((Bandura, 1986, 1997). The highly proficient students may have had more successful language learning experiences than the less proficient ones.

Qualitative results showed that interviewees who had high self-efficacy were more optimistic about enhancing their writing ability and showed more plans and strategies for developing their writing skill than those who felt less efficacious about their writing skill. Combined with quantitative results, this qualitative finding is similar to findings reported by Magogwe and Oliver (2007) and Yllmaz (2010) who found that learners who have high self-efficacy in language learning tended to use more language learning strategies than those with low self-efficacy. The student who reported having high writing self-efficacy appeared to make more efforts and reported to try harder at enhancing their writing skill than low self-efficacy students. The interviewees, who believed in their writing ability, said they frequently used English for their writings while those with low self-efficacy in English writing said they seldom wrote in English or only they wrote in English when they had to. These results are in agreement with a considerable body of previous research which has revealed that self-efficacy is an important factor in determining effort and learning engagement (Bandura, 1997; Busse, 2013; Van de Poel \& Gasiorek, 2012).

The results also indicated that, the participants who had high self-efficacy in writing made more controllable attributions (reasons for their failure or success in something) for writing developments. That is, the participants with high writing self-efficacy pointed to use of appropriate strategies and effort for their success in writing while low efficacious writers mentioned more uncontrollable factors such as lack of content for writing, and task difficulty for their failure in writing. This is in congruence with previous studies in the area of language learning (Graham, 2006; Hsieh \& Kang, 2010). For example, Graham (2006) demonstrated that L2 learners with high self-efficacy attributed their failure to controllable strategies such as lack of effective strategies and insufficient effort while those with low self-efficacy attributed their failure in L2 learning to the lack of ability and task difficulty, factors over which they had no control.

It was also found that participants from science were reported to have a significantly higher level of writing selfefficacy than those majoring in social sciences $\mathrm{t}(302)=4.95, p=.00$. Indeed, the individual differences including language aptitude, strategies, styles, intelligence and motivation of these two groups of students can cast light on the existence of this difference because field of study per se cannot be considered as a significant factor in shaping students' self-efficacy. Rather the characteristics of students in these two broad fields could together affect their self-efficacy. The students in competitive fields of study possess some characteristics such as high abilities and skills which could also affect their self-efficacy. For example, admission to medical sciences is more competitive than other fields, therefore, it would appear that the students who have been accepted into highly competitive fields usually have more positive attitudes and beliefs about their abilities and efforts than those who have encountered failure or were unable to be placed in the highly competitive fields.

It can be inferred that other factors other than students 'field of study, such as effort, intelligence, previous success and failure, self-concept, and social feedback contribute to the development of their self-efficacy. There are many factors other than fields of study which affect the self-efficacy beliefs in a specific area. These factors include intelligence, social persuasion, previous experiences, successful achievements, contextual factors, socio-economic factors, and types of attributions (Bandura, 1997; Kormos \& Kiddle, 2013; Lin, Liang, Yang, \& Tsai, 2013; Moafian \& Ghanizadeh, 2009; Palmer, 2006). In fact, all of these factors appear to affect academic self-efficacy in general and writing selfefficacy in particular. One of the most important factors in determining the level of self-efficacy refers to one's previous successes (Bandura, 1997). Indeed individuals vary in their past successful experiences, and those who experience many achievements usually develop high self-efficacy.

In Malaysia, it is generally a practice for students who demonstrate good language ability and evidence of high school achievements to choose to go for science based disciplines such as medical sciences and engineering rather than social sciences. The students in these fields usually have had successful performance in school subjects and they would have received positive feedbacks and social persuasion. It can be inferred that mastery experiences, intelligence, language aptitude, personal effort, and background knowledge are instrumental in determining one's success in any specific area and in turn the successes result in the development of high self-efficacy. Thus, it is apparent that students in sciences showed higher self-efficacy because their previous mastery experiences have very likely increased their self-efficacy.

This study has some limitations that need to be considered when interpreting the findings. One of the limitations is that the participants were selected from only one university. The data was collected from only one public university in Malaysia, hence affecting external validity and decreasing the ability to generalize the findings of this study to the whole population of undergraduate students in Malaysia. However, it is important to mention that the participants recruited in this research share key common attributes; they all were ESL students; they all belonged to the same course, their age did not vary greatly and they all were raised up in a multi-ethnic context of Malaysia.

Another limitation of this study concerns the self-report data. Since all the students belonged to a writing course, it can be assumed that the use of self-report tools of writing self-efficacy may have resulted in reactivity and self-promotion. That is, the students from the writing course may have tended to provide responses making them look good as they knew they were being measured in some aspects of writing. The participants may have overestimated the seemingly positive traits, and may have provided socially accepted responses rather than their own genuine ones. In addition, the 
validity of the self-report data is largely dependent on the respondents' honesty. Individuals usually tend to give socially acceptable answers rather than their own real answers and hence they want to show responses that make them look good ((Hakkarainen et al., 2001; Hancock \& Flowers, 2001; Rosenfeld, Booth-Kewley, Edwards, \& Thomas, 1996). Furthermore, the writing course may have affected participants' responses regarding writing beliefs, thus the generalization of results to the entire population of Malaysian university students should be viewed with some caution. These limitations should be addressed in future research.

The results of this study have some important implications for L2 writing research and instruction. For the development of L2 learners' writing self-efficacy, teachers should focus on strategies and tactics based on four sources of selfefficacy beliefs (Bandura 1997), vicarious learning, successful experiences, social persuasion, and, techniques for managing anxiety and stressful situations. Teacher must provide opportunities that allow learners to experience successful performance in writing tasks. They can also provide learners with opportunities for vicarious experiences in order to develop learners' self-efficacy, that is, students' self-efficacy beliefs in a particular domain will be enhanced if they observe role models (peers, classmates) successfully perform the given tasks in that area. Teacher also can play a vital role in advancing learners' writing self-efficacy by giving them encouragement, progress feedback and verbal persuasion. Finally, providing L2 learners with support for reducing anxiety and stress in L2 learning environments can be an effective technique for advancing L2 learners' self-efficacy in different domain of L2 learning.

\section{References}

Bandura, A. (1986). Social foundations of thought and action: Englewood Cliffs, NJ Prentice Hall.

Bandura, A. (1997). Self-efficacy: The exercise of control: New York: Freeman.

Busse, V. (2013). An exploration of motivation and self-beliefs of first year students of German. System, 41(2), 379398.

Cheng, Y. s. (2002). Factors associated with foreign language writing anxiety. Foreign Language Annals, 35(6), 647656.

Creswell, J. W. (2012). Educational research: Planning, conducting, and evaluating quantitative and qualitative research (4th ed.). Boston, MA: Pearson.

Cubukcu, F. (2008). A Study on the Correlation between Self Efficacy and Foreign Language Learning Anxiety. Online Submission, 4(1), 148-158.

Dwyer, K. K., \& Fus, D. A. (2002). Perceptions Of Communication Competence, Self-Efficacy, And Trait Communication Apprehension: Is There an Impact on Basic Course Success? Communication Research Reports, 19(1), 29-37.

Erkan, D. Y., \& Saban, A. I. (2011). Writing Performance Relative to Writing Apprehension, Self-Efficacy in Writing, and Attitudes towards Writing: A Correlational Study in Turkish Tertiary-Level EFL. Asian EFL Journal, 13(1), 164192.

Graham, S. (2006). A study of students' metacognitive beliefs about foreign language study and their impact on learning. Foreign Language Annals, 39(2), 296-309.

Hakkarainen, K., Muukonen, H., Lipponen, L., Ilomäki, L., Rahikainen, M., \& Lehtinen, E. (2001). Teachers' information and communication technology (ICT) skills and practices of using ICT. Journal of Technology and Teacher Education, 9(2), 181-197.

Hancock, D. R., \& Flowers, C. P. (2001). Comparing social desirability responding on World Wide Web and paperadministered surveys. Educational Technology Research and Development, 49(1), 5-13.

Hsieh, P. H. (2008). Why Are College Foreign Language Students' Self-efficacy, Attitude, and Motivation so Different? International Education, 38(1), 76-94.

Hsieh, P. H., \& Kang, H. S. (2010). Attribution and self-efficacy and their interrelationship in the Korean EFL context. Language Learning, 60(3), 606-627.

Hsieh, P. H., \& Schallert, D. L. (2008). Implications from self-efficacy and attribution theories for an understanding of undergraduates' motivation in a foreign language course. Contemporary Educational Psychology, 33(4), 513-532.

Kormos, J., \& Kiddle, T. (2013). The role of socio-economic factors in motivation to learn English as a foreign language: The case of Chile. System, 41(2), 399-412.

Lin, Y.-C., Liang, J.-C., Yang, C.-J., \& Tsai, C.-C. (2013). Exploring middle-aged and older adults' sources of Internet self-efficacy: A case study. Computers in Human Behavior, 29(6), 2733-2743.

Magogwe, J. M., \& Oliver, R. (2007). The relationship between language learning strategies, proficiency, age and selfefficacy beliefs: A study of language learners in Botswana. System, 35(3), 338-352.

Manfred, W. M. (2007). The relationships between the use of metacognitive language-learning strategies and languagelearning motivation among Chinese-speaking ESL learners at a vocational education institute in Hong Kong. Asian EFL Journal, 9(3), 93-117. 
Mills, N., Pajares, F., \& Herron, C. (2006). A reevaluation of the role of anxiety: Self-efficacy, anxiety, and their relation to reading and listening proficiency. Foreign Language Annals, 39(2), 276-295.

Mills, N., Pajares, F., \& Herron, C. (2007). Self-efficacy of college intermediate French students: Relation to achievement and motivation. Language Learning, 57(3), 417-442.

Moafian, F., \& Ghanizadeh, A. (2009). The relationship between Iranian EFL teachers' emotional intelligence and their self-efficacy in Language Institutes. System, 37(4), 708-718.

Pajares, F. (1996). Self-efficacy beliefs in academic settings. Review of educational research, 66(4), 543-578.

Pajares, F. (2003). Self-efficacy beliefs, motivation, and achievement in writing: A review of the literature. Reading \&Writing Quarterly, 19(2), 139-158.

Pajares, F. (2006). Self-efficacy during childhood and adolescence: Implications for teachers and parents. In F. Pajares, \& T. Urdan (Eds.), Self-efficacy beliefs of adolescents (pp. 339-367). : Greenwich, CT: Information Age Publishing.

Pajares, F. (2007). Empirical Properties of a Scale to Assess Writing Self-Efficacy in School Contexts. Measurement and evaluation in Counseling and development, 39(4), 239.

Pajares, F., \& Johnson, M. J. (1996). Self-efficacy beliefs and the writing performance of entering high school students. Psychology in the Schools, 33(2), 163-175.

Pajares, F., \& Miller, M. D. (1994). Role of self-efficacy and self-concept beliefs in mathematical problem solving: A path analysis. Journal of Educational Psychology, 86(2), 193-203.

Pajares, F., \& Valiante, G. (1999). Grade level and gender differences in the writing self-beliefs of middle school students. Contemporary Educational Psychology, 24(4), 390-405.

Palmer, D. (2006). Sources of self-efficacy in a science methods course for primary teacher education students. Research in Science Education, 36(4), 337-353.

Pintrich, P. R., Smith, D. A., García, T., \& McKeachie, W. J. (1993). Reliability and predictive validity of the Motivated Strategies for Learning Questionnaire (MSLQ). Educational and psychological measurement, 53(3), 801813.

Rahimi, A., \& Abedini, A. (2009). The Interface Between EFL Learners' Self-efficacy Concerning Listening Comprehension and Listening Proficiency. Novitas-ROYAL, 3(1), 14-28.

Rosenfeld, P., Booth-Kewley, S., Edwards, J. E., \& Thomas, M. D. (1996). Responses on computer surveys: Impression management, social desirability, and the big brother syndrome. Computers in Human Behavior, 12(2), 263-274.

Schunk, D. H. (2003). Self-efficacy for reading and writing: Influence of modeling, goal setting, and self-evaluation. Reading \&Writing Quarterly, 19(2), 159-172.

Stapleton, P. (2001). Assessing Critical Thinking in the Writing of Japanese University Students Insights about Assumptions and Content Familiarity. Written Communication, 18(4), 506-548.

Tilfarlioğlu, F. T., \& Cinkara, E. (2009). Self-efficacy in EFL: Differences among proficiency groups and relationship with success. Novitas-ROYAL, 3(2).

Van de Poel, K., \& Gasiorek, J. (2012). Effects of an efficacy-focused approach to academic writing on students' perceptions of themselves as writers. Journal of English for Academic Purposes, 11(4), 294-303.

Wong, M. S.-L. (2005). Language learning strategies and language self-efficacy investigating the relationship in Malaysia. RELC Journal, 36(3), 245-269.

Woodrow, L. (2006). A model of adaptive language learning. The Modern Language Journal, 90(3), 297-319.

Woodrow, L. (2011). College English writing affect: Self-efficacy and anxiety. System, 39(4), 510-522.

Wu, X., Lowyck, J., Sercu, L., \& Elen, J. (2013). Task complexity, student perceptions of vocabulary learning in EFL, and task performance. British Journal of Educational Psychology, 83(1), 160-181.

Y1lmaz, C. (2010). The relationship between language learning strategies, gender, proficiency and self-efficacy beliefs: a study of ELT learners in Turkey. Procedia-Social and Behavioral Sciences, 2(2), 682-687. 